\title{
Interviews as intraviews: A hand puppet approach to studying processes of inclusion and exclusion among children in kindergarten
}

Kit Stender Petersen kitp@ruc.dk

\begin{abstract}
In this article I will illustrate how our understanding of the interview situation changes when we rethink it with some of the concepts from Karen Barad's notion of agential realism. With concepts such as 'apparatuses', 'phenomena', 'intra-action' and 'material-discursive' (Barad, 2007) it becomes possible to focus more extensively on how matter matters in the interview situation. Re-thinking the interview as an intraview ${ }^{1}$, I argue that Barad's concepts will enhance our awareness not only of how the researcher affects the interview but also of how certain kinds of materiality in interview situations do not merely refer to passive entities but must be understood as matter that matters. To illustrate my points I will analyse how bringing a puppet with me to interviews with 4-6 year old children seemed to interfere with the interview situation creating unforeseen diversions in ways that influenced the children's ways of responding to my questions and re-negotiated the positions of interviewer and interviewee.
\end{abstract}

The purpose of this article is not to convince other researchers to bring a puppet to the field but instead to create an awareness of the fact that both human and non-human agencies influence the interview situation even though we do not always seem to recognize it.

Key words: puppet, bullying, kindergarten, intraview, agential realism, relata

\section{Outline of the theoretical approach}

Karen Barad's (2007) notion of agential realism differentiates between phenomena and apparatus. According to Barad, phenomena can be understood as the basic ontological units that researchers study. This does not mean they should be seen as fixed entities; rather phenomena are produced

\footnotetext{
1 This article is a further development of a paper I presented in Copenhagen in April 2012 at the conference Feminist Materialism with Karen Barad as the keynote speaker. The paper was entitled Interview as intraview, and I made up the neologism for that paper. At that time when I searched the Internet for the word 'intraview' according to a Baradian framework, nothing came up. Later on, however, I have become aware that Kuntz \& Presnall make the same neologism in an article from September 2012. Therefore the present article does not relate to Kuntz \& Presnall's article, but a similiar development and use of the neologism can be found in their article.
} 
through specific intra-actions. Here it is important to clarify that intra-action, according to Barad (ibid), differs from the well-known concept of interaction. While interaction assumes that there are several distinct individual agencies prior to the interaction, the concept of intra-action states that agencies do not precede their intra-action but instead emerge through it and cannot be understood as having clearly defined borders.

In continuation, materiality and discourses cannot be understood separately and prior to the intraaction either. Materiality is discursive just as well as discursive practices always already are material, which means that materiality and discourses always already are intertwined and mutually coconstitutive (ibid). When children see the hand puppet for the first time they will connect it to a repertoire of material-discursive meaning. Whether or not it will be understood as something positive or negative will be connected with here and now and earlier material-discursive actions and experiences. The hand puppet as a materiality is therefore connected to discourses - the children's experiences with puppets - just as the discourses are connected to the materiality - the hand puppet. Therefore the concept of material-discursive does not only embrace the entanglements of bodies and language, but also includes the effects of materiality as something that matters, and not merely reducible or an end product of discourse.

Returning to the concept of apparatuses, these are by contrast what researchers use to study phenomena. "Apparatuses are the material conditions of possibility and impossibility of mattering; they enact what matters and what is excluded from mattering" (Barad, 2007:148). Following Barad it is important to clarify that apparatuses cannot be understood as just laboratory setups or passive instruments for observations. Instead apparatuses must be understood as specific materialdiscursive practices (re)constituted as a part of the ongoing intra-activity of the world. This means that apparatuses do not have intrinsic boundaries; they are open-ended practices (Barad, 2007). However during the intra-actions the apparatuses produce distinctions so that phenomena are given the character of independent entities. "Hence apparatuses are boundary-making practices" (Barad, 2007:148). In my study of inclusion and exclusion among children in kindergarten my research apparatus has been set to examine how bullying seems to be constituted. More specifically I am interested in which and how social dynamics and intra-acting material-discursive forces and processes constitute bullying in kindergarten. How are dignity and contempt produced? How do materialities affect the constitution of bullying? How and why do the subjects relate to each other, in which ways, and how and why do they have a predilection for certain others and certain communities?

The questions in the interviews have been connected to this research ambition and to a certain theoretical framework. If I had been a doctor, my research ambition and questions would no doubt have been different. In that case I might have asked questions about physical symptoms such as stomach pains, weariness and depression connected to being excluded or bullied. The researcher can therefore not be seen as outside the apparatus but must be understood as a part of it. Similarly, other intra-active material-discursive forces such as the interview guide and questions open up certain answers and possibilities while excluding others and thereby make the apparatus a boundarymaking practice. More specifically, this means that phenomena or data, for that matter, do not exist independently prior to the research - the phenomena must be understood as produced by the scientific apparatuses, and these apparatuses are also themselves phenomena. "Phenomena are 
constitutive of reality. Reality is composed not of things-in-themselves or things-behind-phenomena but of things-in-phenomena" (Barad, 2007:140).

In this article I suggest considering the interview situation as an apparatus. Understanding the interview as an apparatus entails that interviews cannot be seen as merely a conversation between two or more separated people in a demarcated room. The room, the doors, the table, the chairs, the interviewer, the interviewee - and in this case also a puppet are always already a part of the apparatus and are intra-acting, just as they are a part of other interwoven apparatuses and intraactions. I will return to later in the analysis. To make this even clearer, the data in the interview situation emerges through intra-activity and material-discursivity and can never be seen or understood as something fixed "out there" waiting to be collected. In the interview situation thinking, acting, doing, etc. are never done in isolation - they are always affected by a wider range of intra-active material-discursive forces - open-ended practices. Yet again we need to address the question of agency, including both agencies of the bodies we understand as 'human' but also the ones we understand as 'non-human' or even 'more than human' (Taguchi, 2012).

\section{Data - Creata - Relata?}

In terms of methodology almost every theoretical tradition today argues that data collection cannot be performed without the researcher affecting it. As Barad puts it, what we see in our data collection is qualified by our doings and iterative practices, which also means that "part of seeing is also being convinced about what one sees" (Barad, 2007:51). This is a seeing that enables us to "discriminate between unwanted noise and desired signal, between fact and artifact" (ibid). With help from Andersen (1994), Stainton-Rogers suggests replacing the word data with the word creata in an attempt to draw attention to the constructed nature of data. As she writes: "Data are always 'creata' - they are constructed by people, and reflect those people's concerns and interests" (2001:199). The researcher's research interests, theoretical inspirations and ambitions of knowledge will always affect the interview situation, framing for example what kind of questions will be asked and whom to ask in the first place. Bendix Petersen writes further, following Stainton-Rodgers:

Using the word creata, she (Stainton-Rogers) suggests, is a way of making the denial of agency impossible, that is, the 'agency' involved in, for example, choosing who to ask, how to ask them, what to make of what they say, what is recognized as 'interesting' and 'relevant' and what goes unnoticed and so on" (...) The point of 'creata' is thus that data are generated, and generated from (multiple and changing) somewhere(s), rather than innocently gathered from the pre-discursive reality and only become discursive the moment they are read and re-presented (Bendix Petersen, 2004:71).

Thinking of data as creata, as Stainton-Rogers points out, means that we have to be aware that data is not something stable that we can go out and collect but must be understood as constructions. By arguing that data is never pre-discursive and that the researcher's ways of asking and deciding whom to ask will always influence the data production, Stainton-Rogers also makes us keep focused on the fact that different agencies influence the data construction.

Understanding data as constructed also influences the scientific knowledge so that this also must be understood as a construction. To further this argument Barad writes: 
The fact that scientific knowledge is constructed does not imply that science doesn't "work", and the fact that science "works" does not mean that we have discovered human-independent facts about nature" (Barad, 2007:40).

Barad's argument fits in well with understanding data as a construction and thereby as creata. But with Barad in mind it is not enough only to understand data as affected by the researcher and by human agencies in general. Barad uses the word relata to incorporate non-human agencies into intra-activity. According to a Baradian lens, data must be understood as emerging out of certain material-discursive intra-actions within phenomena and therefore it also becomes important to pay attention to how non-human agencies affect the data production. Barad writes: "Relata do not preexist relations; rather relata-within-phenomena emerge through specific intra-actions" (Barad, 2007:140).

Therefore relata only exist within phenomena as an outcome of certain intra-actions. There is no such thing as "reality" or pre-existing data to go out to collect separately from the phenomena. Rather the intra-actions within the phenomena enact relata - intra-actions consisting of both human and non-human agencies. Barad puts it this way: "Relata only exist within phenomena as a result of specific intra-actions (i.e., there are no independent relata, only relata-within-relations)" (Barad, 2007:465). Following Barad's thinking, relata must therefore be understood as emerging from certain intra-actions within phenomena. I will return to these conditions in the analytical examples.

\section{The interview situation}

Before I started my fieldwork the children were told that I wanted to write a book about how they experienced their everyday life in kindergarten, how and why they became friends and some times fell out with each other and how this could affect their days in kindergarten.During my fieldwork I observed the children's everyday life in kindergarten for about two months. I was interested in getting access to how the children related to each other and to the kindergarten teachers. Some of my questions were: How did they create communities? How was it possible for the children to enter them? Who could enter them? How were contempt and dignity produced in relation to one another?

After this I interviewed the children one by one in an attempt to get access to their stories about why they related to each other and to the kindergarten teachers in certain ways and how friendships and exclusion practices affected these relation practices. Who did the children think of as their friends? What made a good friend? Who didn't they like to play with? Had they experienced being excluded from a game? How did it feel? Were they or others excluded often? Why? Before I conducted the interviews, the idea of sitting at a table interviewing the children one by one in one of the kindergarten rooms made me ask myself how this situation would make my position any different from that of the kindergarten teachers. Even though I had been present in the kindergarten for a couple of months observing the children's everyday life ${ }^{2}$, the interview situation would re-negotiate my position once again, bringing the children into a room behind a closed door asking them

\footnotetext{
2 In the observation period I did not bring the puppet. For further discussions of this see Stender Petersen, (in prep.).
} 
questions. However, I found such conditions necessary to create an atmosphere of confidentiality and privacy.

The room chosen was one which the children could relate to since different kinds of formal tests and environment studies carried out by the kindergarten teachers had also taken place in the same room. This was the only room where the children and I could sit undisturbed since all the other rooms had large windows allowing the children being interviewed to see their peers playing and walking past and to be seen themselves by their peers. I did not find these conditions comfortable for an interview situation containing difficult and emotional topics and questions. I had an idea that if the children were able to see their peers during the interview it would not convince them of the confidentiality of the situation: If I can see them, why shouldn't they be able to hear me? In choosing this room it was important for me to try to create a different kind of interview situation and experience of the room, compared to the room they were used to from earlier interviews and formal tests.

Bringing a hand puppet, along with paper, pencils and toys, I hoped to make the room look more like their daily settings and thereby make it meaningful and comfortable for the children to participate in the interviews. I also told the children that they could bring whatever they wanted to the room when it was their turn to be interviewed. Some brought toys, some brought sticks from the playground and some did not bring anything. Before the interviews took place, the children were asked whether or not they wanted to participate and if the time suited them. Even though every child had to give me his or her permission to participate I was aware that this permission could be temporary and that there could be a discrepancy between verbal and bodily consent (Alderson, 2004; Harcourt \& Conroy, 2009). I kept this factor in mind throughout all the interviews. The children were told in the beginning of the interview that they could leave the room whenever they wanted to, that every answer was a good answer, that they could sit on a chair, on the table, on the floor or even walk around as long as we stayed in the room. I wanted to know their stories and I thought of them as experts on kindergarten life. I kept in mind that if any child started to seem uncomfortable with the interview I would ask them if they were okay or wanted to do something else; however, this did not turn out to be necessary since all the children completed the interviews with interest and some even wanted to stay longer to answer more questions or play with the hand puppet.

\section{Say Hello to Muffin the Puppet}

To be able to show analytically how the hand puppet as a non-human agency was able to gain agency in the interviews and how this could matter, I would like to introduce you to Muffin the puppet. I designed the puppet myself and had a seamstress make it. It came out looking like a big white "dust mouse" with big ears, long light brown arms and legs, big eyes and a mouth you could open and close by putting your hand inside it. I chose colours that I imagined would not relate to certain genders, just as I named it Muffin in an attempt to give it a more or less gender-neutral name. I also chose not to talk "through it" or on behalf of it, and if the children asked me whether or not it could speak, I told them that it could speak, but probably was too shy at the moment. The reason I made these decision was because I was afraid that if I read certain meanings and opinions into Muffin I would be risking some of the children's possibilities of connection with Muffin. I wanted the meanings connected to the hand puppet to be on the children's conditions. I hoped that trying to 
avoid gender-related material-discursive meanings could and would allow the children to intra-act with Muffin in ways that would leave space for their own fantasies and meaning-making.

Soft toys and dolls have been used in several studies and conversations with children, mainly in a therapeutic way to try to change children's behaviour or in relation to help sexually abused children to talk about what happened when the abuse took place (see e.g. Bender, 1936; Morgan, 1995; DeLoache \& Marzolf, 1995). In these conversations the dolls and soft toys are used as "selfrepresentation tools", meaning that the children are supposed to think of the dolls as themselves and as an example to show the grown-up what they have been exposed to.

My purpose in bringing Muffin was not connected to these matters. I wanted Muffin to be "in its own rights" and not a reflection of the child. I hoped that the presence of Muffin would give the children a feeling of having an "ally" or something familiar and could help unsettle the power structures between the children and me as a grown-up, to create a secure and conducive environment. Morgan, Gibbs, Maxwell and Britten (2002) had a similar interest when they conducted focus group interviews with 7-11 year old children in their study of methodological issues. They brought a soft toy formed as a dragon to the interviews and they found that its presence convinced the children that their knowledge and perspectives were important.

In my study I had an ambition of not being recognized as a kindergarten teacher since I wanted the children to be able to tell me whatever they liked to without being unsure of whether or not I would regulate or judge their stories. Having this in mind I had the intention to separate the interview situation from other events to allow for a different positioning as "another kind of grown-up" (for similar attempts see also Mandell, 1991; Fine and Sandstrom, 1988; Thorne, 1993; Pollard and Filer, 1996; Mayall, 2000) to enable me to gain access to a different kind of knowledge. Such knowledge would allow me to gain new insights into the sides of children's everyday life that are less often told to the adults in charge of them. They should be able to tell me if they had teased other children, hurt someone, had been teased or hurt themselves, etc. Entering the kindergarten front door every morning in the interview period with Muffin on my arm, I quickly became the companion of Muffin and had to carry drawings and other gifts to Muffin from the children or decide whether or not Muffin could come outside and play when the children asked for such permission. At intervals the children also questioned me and Muffin's reliability asking: "Muffin never lies, does it?" or "Muffin is not a real human being, is it?" just as they could express a certain kind of affinity with me and Muffin saying: "It's just us. You, me and Muffin" or even hiding some of their food from the kindergarten teachers and bringing it to Muffin to make sure it wouldn't go hungry. This made me discover that Muffin seemed to have gained more agencies than I had ever thought possible. It seemed that Muffin was never treated as "just" a toy; the children always showed it a great amount of respect and whenever we entered the kindergarten front door both children and teachers gazed at Muffin and said "Good morning, Muffin" acting as if it had come through the door on its own without my presence.

Even though I hoped that bringing Muffin with me to the field could help disturb the positioning, I was still aware that in an interview situation it is often the interviewer who has the most powerful position. It is the interviewer who asks the questions, controls the situation, determines the agenda etc. (Ramos, 1989). This is necessary in many ways since the interview has a research purpose that needs to be fulfilled but these matters seem to be even more powerful where children are 
concerned. Attempting to view the interview situation through a Baradian lens, I hoped that Muffin would intra-act with other present material-discursive forces in ways that would let me hold the framework of an interview situation in place, but at the same time de-territorialize the power structures between the child and me as a researcher. Taking Muffin with me to the field was an opportunity to try to provide both stability in relative ways according to an interview situation, and open up for possible change, but by doing so we were moving into the not-yet-known. To show how this not-yet-known-ness came to matter, I will give three empirical examples from my interviews with Liam, Adam and Hailey ${ }^{3}$. All three examples invite the reader into different intra-active practices showing how different kinds of relata emerge and thereby also showing how the puppet approach seemed to re-negotiate the interview situation as well as the interviewer and interviewee positions affecting the relata that emerged.

\section{Dead or alive?}

Liam was the first child who made me reflect on how Muffin seemed to gain agency and affect the relata emerging in different ways, according to who and what intra-acted with it and how. In the interview with Liam he asked me if he could hold Muffin for a while. Standing there with Muffin in his hands stroking its white fur, he suddenly asked me: "Muffin is just a soft toy, isn't it? I paused for a couple of seconds and then I said: "Well... yes maybe?" Liam quickly asked again, looking into my eyes: "But you don't think so, do you?" This time I was a bit faster and answered: "No". A big smile of approval appeared on Liam's face. He looked back at Muffin and then he said: "Neither do I!"

The first thing that came to my mind was that Liam seemed to be entangled in material-discursive intra-actions saturated and permeated with each other. Through Liam's questions it seemed that Liam was entangled in discourses saying that toy animals are just toy animals. They are not something with the capacity to live, move and act. But even though these discourses seemed to mix with Liam's ways of thinking, his presence in the interview room placed by a closed door, his imagination and the intra-actions of Muffin, himself, me as an alternative kind of grown-up and my answers seemed to make him wonder and didn't totally convince him. Maybe toy animals are alive? Maybe we just never notice? And maybe it's time to reveal their secret?

Many of the children were sitting down during the interviews, some on a chair, some on the table, and even some on the floor. But no matter where they were, they placed Muffin close to them during the interview. Muffin had to sit on their lap, on the chair next to them, sometimes even next to them on the same chair, carried in their arms while they were walking around, or close to them on the floor. This included Liam. During the interview Liam carried Muffin in his arms while he was walking back and forth in the room cuddling it and even feeding it with dry bananas and raisins (these snacks were actually meant for Liam to eat). In this situation the paper, pencils and toys I brought to the room seemed unimportant to Liam. He kept holding Muffin close to his stomach, placing his arms around it and sometimes sticking his nose into the fur on the top of its head while he was walking around.

\footnotetext{
${ }^{3}$ All names in this article have been changed to protect the identity of the children. All the names are therefore pseudonyms.
} 
Many times during the interview Liam suddenly interrupted my questions and started asking me questions instead: "How old is Muffin?", "Does it have any parents?", "Do you think it likes sitting here?", "Did you see that?! It just took a raisin and ate it!!" The comments and questions connected to Muffin's intra-actions with Liam seemed to re-negotiate the positions between Liam and me as a researcher, and in periods of the interview Liam took the position of the interviewer, positioning me as the interviewee. In the situation I let Liam ask his questions and I answered them as well as I could. Letting Liam ask me questions seemed to produce a more equal relationship between us in the interview situation. The shift in positions made the interview closer to a conversation living up to the expectations of both of us.

For Liam, coming for the interview clearly also had a certain purpose that intra-acted with the interview situation - being with Muffin and getting to know it better. This knowledge made me aware that even though I as an interviewer was also taking part in the interview with a specific purpose, the child may not know or understand this purpose completely or may be attending the interview with a completely different purpose. Letting Liam fulfil his purpose seemed to make it easier for me as a researcher to get him to answer my questions and it also seemed easier to keep his attention on the interview for an extended period. Not only Liam but also the other children seemed to enjoy the interview situation in ways that made me follow the interview guide to completion. On average the children were in the interview situation for 45-60 minutes and in some cases the children did not want to leave the interview room after the interview was done. They wanted to stay answering and/or asking more questions and playing with Muffin. The intra-actions between Muffin, Liam, me as a researcher, the room, the interview situation, questions asked and answered, our different purposes, etc. made a different kind of relata emerge. These relata showed how positions changed, how power relations broke down and how attention was attracted and maintained. The presence of tables, chairs, toys, etc. seemed to remain in the background of the intra-actions even though they still had agency in terms of their presence and influence on how for example our bodies could move, sit and act during the interview.

\section{Naughtiness re-negotiated}

In the interview with Adam more material-discursive agencies had an influence on the interview and on the relata emerging. In this interview Adam and I were sitting on the floor. Adam was sitting with his back to the closed door. I was sitting in front of him and Muffin was placed next to both of us, sitting on the floor as well. Adam was about to make a drawing for Muffin and we were talking about how Adam sometimes bothered some of the other children. Adam told how he sometimes pushes the other children and actually finds it rather fun even though they tell him to stop. But Adam also told me that the fun part always stops when the teachers see it and start yelling at him and controlling him. Therefore he needs to keep track of where the teachers are, so he can bother others without being discovered. During the interview I realized that Adam chose to look at Muffin when he talked about bothering other children. Later on in the interview he even looked straight into my eyes asking me: "Muffin also listens to me, doesn't it?" Here it can be important to emphasize that even though Adam chose to look at Muffin when he answered questions, I still presume that he knew that I would hear his words. If he hadn't wanted me to hear, he could have chosen to whisper into Muffin's ear, but in fact he did not. 
Returning to Barad's concepts, she reminds us that artefacts and materiality must be understood as performative agents in their intra-activities with each other and with humans. Everything is mutually entangled in non-hierarchical relations and we can never know beforehand which agencies will emerge from the intra-actions. Agencies are not something someone or something has prior to the intra-action. Analysing the interview situation with Barad's concepts enables an awareness of how the closed door and Muffin as materialities seem to intra-act with Adam and make it possible and comfortable to talk about "bad behaviour" and the fact that Adam finds this behaviour amusing and exciting. The intra-action between the closed door behind Adam and the presence of Muffin as a participant listening with care to his tellings without judging him opened up for secrets to be told and the closed door underlined confidentiality and that what we talked about would not reveal Adam's identity. What emerged out of these intra-actions is that Adam seemed to position both himself and me in new ways.

When Adam looks at Muffin and gives me detailed descriptions of familiar bad behaviour, Adam seems to reposition himself and becomes something other than he was. Something different from when he is in the everyday kindergarten setting, which includes the everyday presumption of his own position as a naughty child and the position of grown-ups as people you must hide your teasing stories from. In the material-discursive intra-action with Muffin, the closed door, the questions and me as a researcher, he seems to escape from some of his limitations bound in the striations of appropriateness and the power relation between him as a child and me as a grown-up, and through the intra-actions a certain kind of relational space seems to emerge.

In this space Adam tells in detail how he feels and thinks about the episodes without worrying about the researcher's position as a grown-up. It seems that the familiar inappropriate child for a moment does not exist in these intra-actions and that the intra-actions make Adam trust me as another kind of grown-up, letting me get access to and listen to his stories of 'bad' behaviour. When Adam looks at Muffin it seems that Muffin and the closed door as materialities gain agency in ways that deterritorialize the power structure between me as a researcher and Adam as a child, because they offer Adam another way of communicating - a way where he can choose to look at Muffin, and a space where Muffin and the closed door seem to allow for a different kind of telling and positioning. The intra-actions between Muffin, the closed door, Adam and me create a situation where Adam seems to understand Muffin as a friend and "on his side". This makes the interview situation negotiated in new ways. What may not seem proper to say to an adult alone finds a voice because of Muffin being present and because of the closed door marking a special kind of room, thus affecting the relata emerging and giving me as a researcher saturated and differentiated insights into Adam's understandings of the kindergarten environment.

\section{Crossing bodies}

In the interview with Hailey we were both sitting at a table on chairs facing each other. Hailey wanted us to sit like this and had placed Muffin close to herself so that it was sitting on the table facing her. We talked about her being denied access to certain games - and according to Hailey this is often controlled by Sofie. When I asked her if she thought Sofie didn't like her, Hailey suddenly looked at Muffin, grabbed it, held it up to her own ear and said: "It's whispering something". A little surprised I asked her: "What is it?" Hailey looked down into the table, now hugging Muffin, and answered: "It said no." Not quite sure what she meant, I asked again: "No to what?" Hailey clarified 
further with a sad voice: "It doesn't think Sofie likes me". I asked: "How does it know that?" and Hailey looked up shrugging her shoulders and said: "It just knows...".

Contrary to the interview with Liam, in this interview with Hailey the intra-actions of the table and the chairs seemed to gain certain agency in ways that affected the interview situation. In one of Taguchi's analyses of how tables and chairs seem to matter to an interview, she writes: "I install myself in the space where the adult interviewer brings one child at a time to a table to perform an interview. In this space, the table and chairs enact a space of interviewing. (...) The table actively separates and distances the adult from the child. The table can be felt to agentially enact distance" (Taguchi, 2012:275).

In the interview space with Hailey similar matters seem to matter. The intra-actions between the table, the chairs and the difficult question that arouses certain feelings of sadness, agentially seem to enact a material distance between Hailey and me as the interviewer. The distance makes it impossible for me to put my arm around Hailey's shoulder to show her that it is okay to feel sad, but the presence of Muffin and its way of entering the intra-actions produces an opportunity for Hailey to seek comfort and strength to answer the question through Muffin. Muffin disturbs the distance produced by the chairs and the table and seems to create a way of interviewing children distinct from other material-discursive events where children talk to adults.

When Hailey provides Muffin with the ability to talk it seems to break down the striations of the interview situation. Suddenly Muffin is the knowing part answering questions and this creates another kind of interview where more voices come to matter and where different kinds of positionings become possible. Yet again Hailey's telling doesn't seem restricted to her own body. Following Barad's thinking, Muffin as a materiality intra-acts with Hailey's telling, my questions, our ways of sitting, etc. When Hailey provides Muffin with the ability to talk, or in other words speaks through it, it seems to break down the sealed demarcation between Muffin and Hailey. The agency of Muffin emerges out of the intra-actions between the furniture, the question, the interview situation, etc. and disturbs the striated interview situation; so that becoming is not just restricted to Hailey's own body but crosses its striations when Hailey gives Muffin life. When Hailey during the intra-action imbues Muffin with life, it provides her with the ability to tell a different kind of story than would have been possible without it. This again allows for the emergence of different answers and relata than would otherwise have been possible.

\section{Interview vs. Intraview}

In relation to the analytical examples I find it important to increase the awareness of how materialities affect the interview situation. To do this I find it fruitful to make a neologism by changing the word interview to intraview. The change in terminology signifies that the intraview must be understood as a set of material-discursive intra-actions allowing certain relata to emerge instead of a situation where the main focus is on how two (or more) distinct human beings interact with each other. As shown in the analysis this understanding also means that the interviewer and interviewee cannot be understood as consisting of a centred essence remaining the same throughout time but must be understood as coming into existence through the encounter with other material-discursive agencies and intra-actions (Barad, 2007). This perspective affects the relata emerging and the understanding of time and place since "the past is not some static being, and it is 
not a previous present, nor a present that has passed away; the past has its own dynamic being which is constantly renewed and renewing" (Colebrook, 2002, p. 77).

Changing the word interview to intraview can help us keep in mind that in this line of thinking relata emerges from intra-actions with both human and non-human agencies and is never 'out there' to be collected. The length of the interview, the research questions, the questions asked, the furniture, a closed door, etc. can matter. Thus a change in any of these parameters can make the emerging relata significantly different. According to Barad, however, there will always be some agencies standing out more than others according to which apparatus, phenomena and which intra-actions they are part of. The research apparatus in intra-action with the phenomena being examined has relevance to which materialities stand out as important due to the intra-actions. Since it is the children's tellings and experiences I am interested in getting access to, it seems to be the intra-active materialdiscursive forces encouraging or blocking such tellings that stand out as important in this research apparatus.

Though it is impossible to spot and specify all intra-active agencies intra-acting in the intraview apparatus, the awareness of their impact may help us to understand relata as 'emerging' instead of a representation, a mirroring or something collectable. It will also help us to understand the interviewee's stories as enactments rather than descriptions (Jackson \& Mazzei, 2012). Further, it can help us keep in mind that the researcher is also a performative agent being reinvented in the interview situation. "We engage our whole bodyminds to try to read the flows and passages where life continuously emerges in an immanent flow of potentialities and becomings, rather than trying to uncover the constitutive phenomena for our 'being-in-the-world'" (Hultman \& Taguchi, 2010:537). Creating the neologism intraview and thinking of data as relata and as mutually constituted and as emerging instead of ready for collection positions the researcher and other material-discursive agencies as important in the intraview and requires us to consider how these agencies intertwine and how they matter to the relata emerging. It is not unimportant from which intra-actions relata emerge nor how non-human agencies intra-act with and impact the data emerging.

\section{Conclusion}

The ambition of this article was to illustrate what happens to the understanding of data when we think of the interview situation as different kinds of material-discursive intra-actions, and consider what kind of agencies seem to emerge out of these and how this seems to affect the production of data. In the analytical examples I have shown how Muffin as an important materiality gained agency in certain ways, even though I am also aware that bringing a puppet with me to an interview enables some possibilities while preventing others. In showing how Muffin together with other materialities such as furniture gained agency I have tried to illustrate that thinking with Barad gives us new vocabulary and provides us with the ability to investigate how relata emerges in interview situations.

The Baradian concepts opened up the ability to understand how materialities gained agency by becoming entangled in the material-discursive enactments of the relational interview situation with the children and me as a researcher, how the intra-actions made something not-yet-known emerge and how it affected the children's material-discursive positionings and the relata emerging. With the examples of Liam, Adam and Hailey I have shown how a hand puppet as a discursive-materiality can 
gain agency in different ways through various kinds of intra-actions. Muffin could be present in the situation as an interviewer, an interviewee, a friend, a listener, a voice, etc.

Even though Muffin was not alive in the sense of having a beating heart, the ability to talk, etc., Muffin was not a passive entity in the interview situation. Instead it was an active material agent that allowed for new questions, answers and positions in the encounters between the children, me as a researcher and other agents and through these intra-actions it became clear that Muffin gained agency in ways where in the children's eyes it listened, acted, and even talked. Bringing Muffin to the field made a different kind of interview situation emerge, i.e. one where the ground rules of the interview could be fulfilled (getting the children to answer questions connected to the ambition of knowledge) but also a situation where the children's bodies could intra-act and transform themselves in many different ways - and not only as the familiar appropriate or inappropriate children trapped in the kindergarten's everyday striations. Similarly, it enabled new unknown positions for me as a researcher such as an interviewee, the companion of Muffin or another kind of grown-up.

Focusing on the intra-activity in the encounters between the children, Muffin, me as a researcher, the furniture, the questions, etc. helped to clarify that not only relations between subjects have an effect on the production of relata. Which narratives come to matter changes depending on what intra-actions and apparatuses the child and me as a researcher become and seem to be a part of. Depending on discourses, materialities including which apparatuses we as researchers are a part of, research questions, what questions we pose in the interviews, what theories and methods we draw on, and what kind of material-discursive intra-actions these seem to be entangled in will create what I here rename intraviews, precisely because there are no distinct entities in the interview situation. My main point is therefore that if we reconsider our data as relata through an agential realist lens it will provide us with a sharpened ability to keep in mind that those interviewed are not independent but a product of intra-actions, that materiality is not passive but has a considerable influence on what can be said and done in an intraview, and that intraviews at the outset are always open-ended practices that will provide us with different relata and knowledge according to what intra-acts and what seems to emerge out of these intra-actions.

\section{References}

Alderson, P. (2004): Ethics. In: S. Fraser, V. Lewis, S. Ding, M. Kellett, \& C. Robinson (Eds.), Doing Research with Children and Young People (97-112). London: Sage.

Andersen, M. L. (1994): The many and varied social constructions of intelligence. In: T. R. Sarbin \& J. I. Kituse (Eds), Constructing the Social (119-138). London: Sage.

Barad, K. (2007): Meeting the Universe Halfway. Durham and London: Duke University Press. http://dx.doi.org/10.1215/9780822388128

Bender, L. \& Woltmann, A. G. (1936): The use of puppet shows as a psychotherapeutic method for behavior problems in children. American Journal of Orthopsychiatry, 6(3), 341-354. http://dx.doi.org/10.1111/j.1939-0025.1936.tb05242.x

Bendix Petersen, E. (2004): Academic Boundary Work: The Discursive Constitution of 'Scientificity' 
Amongst Researchers Within the Social Sciences and Humanities. PhD dissertation, Department of Sociology, University of Copenhagen.

Colebrook, C. (2002): Understanding Deleuze. Crows Nest, Australia: Allen \& Unwin.

DeLoache, J. \& Marzolf, D. (1995): The Use of Dolls to Interview Young Children: Issues of Symbolic Representation. Journal of Experimental Child Psychology, 60(1), 155-173. http://dx.doi.org/10.1006/jecp.1995.1036

Fine G. A. \& Sandstrom K. L. (1988): Knowing Children: Participant Observation with Minors. Newbury Park: Sage. http://dx.doi.org/10.4135/9781412984706

Harcourt, D. \& Conroy, H. (2009). Informed agreement to participate: Beginning the partnership with children in research. Early Child Development and Care, 179(2), 157-165. http://dx.doi.org/10.1080/03004430802666973

Hultman, K. \& Taguchi H. L. (2010): Challenging anthropocentric analysis of visual data: a relational materialist methodological approach to educational research. International Journal of Qualitative Studies in Education, 23(5), 525-542. http://dx.doi.org/10.1080/09518398.2010.500628

Jackson, A. Y. \& Mazzei, L.A. (2012): Thinking with theory in qualitative research: Viewing data across multiple perspectives. London: Routledge.

Kuntz, A. \& Presnall, M. (2012): Wandering the tactical: From Interview to Intraview. Qualitative Inquiry, 18(9), 732-744. http://dx.doi.org/10.1177/1077800412453016

Mandell, N. (1988): The least adult role in studying children. Journal of Contemporary Ethnography, 16(4), 433-467. http://dx.doi.org/10.1177/0891241688164002

Mayall, B. (2000): Conversations with children: working with generational issues. In: P. Christensen, A. James (Eds), Research with Children: Perspectives and Practices (120-135). London: Falmer Press.

Morgan, M. (1995): How to interview sexual abuse victims, including the use of anatomical dolls. Newbury Park, CA: Sage Publications. http://dx.doi.org/10.4135/9781483326849

Morgan, M., Gibbs, S., Maxwell, K. \& Britten, N. (2002): Hearing children's voices: methodological issues in conducting focus groups with children aged 7-11 years. Qualitative Research, 2(1), 5-20. http://dx.doi.org/10.1177/1468794102002001636

Pollard, A., Filer, A. (1996): The Social World of Children's Learning. London: Cassell.

Ramos, M. C (1989): Some ethical implications of qualitative research. Research in Nursing and Health, 12(1), 57-63. http://dx.doi.org/10.1002/nur.4770120109

Stainton-Rogers, W. \& R. (2001): The psychology of gender and sexuality. Buckingham: Open University Press. 
Stender Petersen, K. (in prep.): Mobning i børnehaven [Bullying in the Kindergarten]. PhD dissertation, Roskilde University.

Taguchi, H. L. (2012): A diffractive and Deleuzian approach to analysing interview data. Feminist Theory, 13(3), 265-281. http://dx.doi.org/10.1177/1464700112456001

Thorne, B. (1993): Gender Play: Girls and Boys in School. New Brunswick, NJ: Rutgers University Press. 